\title{
Study of Prescribing Pattern and Impact of Pharmaceutical Care in Bronchial Asthmatic Paediatric Patients in a Tertiary Care Teaching Hospital
}

\author{
Vengala Bhavan Kumar"1, Tina Mariam Thankachan', Anuradha Amanapu', Devineni Surya Chandra ${ }^{1}$ \\ and Sundararajan Parimala Krishnan ${ }^{2}$
}

1'Department of Pharmacy Practice, Rajah Muttiah Medical College and Hospital (RMMCH), Chidambaram-608001, India.

${ }^{2}$ Department of Pharmacy, Annamalai University, Chidambaram-608001, India.

\begin{abstract}
Background: Asthma is a chronic inflammatory disease of increasing prevalence that is a result of genetic predisposition and environmental interaction and one of the most common chronic diseases of childhood. Aim and Objective: The aim is to study the prescribing pattern and impact of pharmaceutical care in bronchial asthmatic paediatric patients. The present study was conducted in RMMCH, Chidambaram. Over a six month period patients who were diagnosed with Bronchial asthma was enrolled and the information was gathered using validated data collection form. The overall asthma cohort included in the study based on inclusion criteria. Subjects under 12 years of age, and who are newly diagnosed and admitted in paediatric wards for Bronchial asthma. Results: A total of 61 patients were included out of which $43(70.4 \%)$ are boys and 18 (29.6\%) are girls. $\beta$-agonists (Salbutamol, Ipratropium bromide) accounts for highest number of 51 out of 61 prescriptions. Among antibiotics crystalline penicillin was present in highest number of prescriptions (86.8\%). Drugs used in RMMCH were compared to various EDL (Essential drug list) which complied with national EDL. The pharmaceutical care outcomes was measured and a significant difference was observed between the lung functions tests (FVC; $\mathrm{P}=<0.001)$ and (FEV; $\mathrm{P}=<0.008)$. Which indicates the improvement of pharmaceutical care from control (30 without intervention) to test ( 31 with intervention) group. There is a statistically significant difference between the test and control group at $(\mathrm{P}=<0.001)$. Conclusion: Patient education produced a substantial improvement in patient counselling, understanding of their illness and role of medication and its treatment. Pharmaceutical care services provided by the pharmacist improved quality of life, medication adherence in test subjects. Interventions aimed at improving therapeutic outcomes in bronchial asthma.
\end{abstract}

Key words: $\beta$-agonists, Bronchial asthma, Medication adherence, Pharmaceutical care, Prescribing Pattern, Quality of life.

\section{INTRODUCTION}

Asthma is a disease of increasing prevalence that is a result of genetic predisposition and environmental interactions and one of the most common chronic diseases of childhood. It is characterized by recurrent attacks of breathlessness and wheezing, that may vary in severity and frequency from person to person. ${ }^{1}$ Asthma is a chronic inflammatory disorder of airways. Asthma is thought to affect $3 \%$ of population in most countries. ${ }^{2}$ Asthma is one of the most commonly under diagnosed and untreated disease which further creates substantial burden on individuals and their families. ${ }^{3}$
Three to five percent of paediatric population in India is affected by asthma where as in adults it ranges from $3-11 \%{ }^{4}$ In this study, an attempt has been made to study general prescribing pattern impact of pharmaceutical care based on therapeutic regimen prescribed, counseling patient on disease condition, medication use, and medication Adherence. ${ }^{5}$ In order to improve patient's health, pharmaceutical care has to be implemented by clinical pharmacist which includes activities like monitoring patient's symptoms, counselling patients about their medications, helping to resolve
Submitted date :26-Jan-2015 Accepted date :16-Feb-2015

DOI: $10.5530 /$ ijopp.8.1.8

Address for correspondence: Mr. V. Bhavan Kumar, Department of Pharmacy Practice, Rajah Muttiah Medical College and Hospital (RMMCH), Chidambaram-608001, India Phoneno:9042915174

E-mail:bhavan.hari@gmail.com

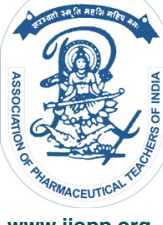

www.ijopp.org 
Drug-related problems. This study was performed to show the impact of pharmaceutical care plan in the patients with asthma. Bronchial asthma has an appropriate focus of pharmaceutical care because it is a chronic disease which requires ongoing therapeutic monitoring. The acute exacerbations of asthma leading to morbidity, increased cost and death often preventable. ${ }^{6,7}$

Adherence is a primary determiner of the effectiveness of treatment because poor adherence attenuates optimum clinical benefit. Good adherence improves the effectiveness of interventions aimed at promoting healthy lifestyles, such as diet modification, increased physical activity, and of the pharmacological-based riskreduction interventions. It also affects secondary prevention and disease treatment interventions. ${ }^{8}$

This study aims at current prescribing pattern of asthmatic medications in patients below 12 years and the role of pharmacists in improving patient's health.

\section{MATERIALS AND METHODS}

The study was a non-invasive, observational, prospective, cohort study carried out over 6 month period incorporating both descriptive and inferential analyses. The study was approved by the Institutional Human Ethics Committee \& Informed Consent Form was obtained from the eligible patients. Patients were selected on the basis of inclusion criteria and exclusion criteria.

Patients of age group below 12 years who were prescribed with at least one anti- asthmatic drug, Patients who were diagnosed with bronchial asthma and under prescription are included in this study. Patients who were not willing to cooperate, Patients who were having other respiratory problems, cardiac problems are excluded from this study.

The patients were further classified into 3 age groups $0-4,5-8$, and $9-12$ years (as shown in Table 1). Convenient sampling was used to recruit all eligible patients a validated data collection form was used to collect data from the patients. The data collection form provides the information regarding the demographic details of the patient which includes age, sex, past history, family history, medication history and treatment giving to the patient. Participants were inquired about their understanding while completing the form. Their feedbacks were then used to improvise data collection for their easy understanding. In the present study the prescribing pattern was conducted to evaluate the drug- prescribing trend of anti-asthmatics drugs by physicians in RMMCH (Rajah Muttiah Medical College and Hospital). In this study the categories of drugs, antibiotic prescribing pattern, drug therapy regimens, list of drugs complying with WHO (World Health Organisation),

\begin{tabular}{cccc}
\multicolumn{4}{l}{ Table 1: Demographic Characteristics } \\
\hline \multirow{3}{*}{ GENDER } & n & $\%$ \\
\hline & Boy & 43 & 70.4 \\
& Girl & 18 & 29.6 \\
& Total & 61 & 100 \\
& $0-4$ & 15 & 24.6 \\
AGE (in yrs.) & $5-8$ & 21 & 34.4 \\
& $9-12$ & 25 & 41.0 \\
& Total & 61 & 100 \\
\hline
\end{tabular}

$\mathrm{n}=61$ (sample size)

NATIONAL, T.N (Tamil Nadu) essential drug list was analysed by including the number of prescriptions. Finally a cohort 61 prescriptions were screened and results were tabulated according to their percentages and number of prescriptions.

In pharmaceutical care sector quality of life was measured by using the paediatric asthma care givers Quality of life (QoL) questionnaire. Medication adherence was adopted by using Morisky adherence scale and the results are interpreted based on the level of adherence as low, medium and high. ${ }^{9}$ In this present study analysis was carried out by comparing test and control groups. All the 61 patients are divided in to two groups and intake was performed in equal proportion with similar age groups and disease condition. Pharmaceutical care intervention was provided to the test group and results were interpreted, whereas in control group results were interpreted without any intervention during the study period. A statistical test was performed using student $t^{\top} \mathrm{t}^{\prime}$ test using the statistical package for social sciences version 16 (SPSS Inc, Chicago, IL, USA) for the analysis of data at a significance level of $\mathrm{P}=<0.001$. This level of significance is obtained at 60 degrees of freedom, 95\% confidence interval. After the completion of study the pharmaceutical care was provided evenly to both test and control group.

\section{RESULTS}

\section{Patient Characteristics}

A total of 67 patients were approached of whom 61 patients agreed to participate in the study. Out of which $43(70.4 \%)$ are boys and $18(29.6 \%)$ are girls. At the beginning of the study the patients are divided based on intervention into test group and control group (30 controls and 31 tests). Majority of the patients were in the age group of $9-12$ years (41\%) followed by $5-8$ years $(34.4 \%)$. Climate is the primary cause of bronchial asthma accounts for $55 \%$ followed by dust and pollens. Represented in (Figure 1). 


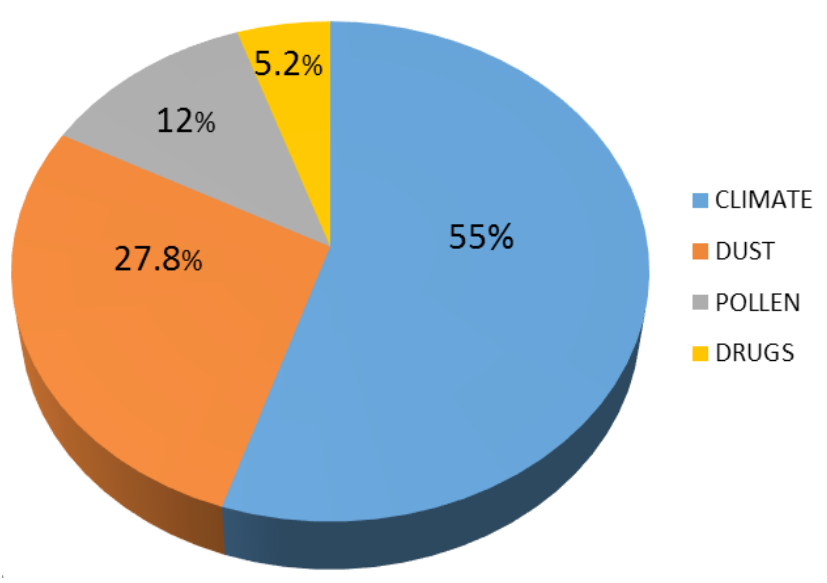

Figure 1: Causes of Asthma

\section{Prescribing pattern}

$\beta$-agonists (Salbutamol, Ipratropium bromide) accounts for highest number of prescriptions i.e, 51 prescriptions followed by Corticosteroids (Hydrocortisone, Prednisolone, beclomethasone) and methylxanthine (Theophylline), 25 and 23 prescriptions respectively (shown in Table 2). Whereas Anti-Histamines are the least prescribed category drugs. Crystalline penicillin was present in highest number of prescriptions $(86.8 \%)$. Followed by Amikacin (77\%), Gentamycin (73.7\%), and Ampicillin $(54 \%)$. Multiple drug therapy was the most common type of drug therapy regimen prescribed in most of the prescriptions. In this study drugs used in $\mathrm{RMMCH}$ were compared to various EDL (Essential drug list) and it was found that $100 \%$ of drugs are complied with national EDL (shown in Table 3). List of all anti-asthmatic drugs mentioned in WHO EDL, National EDL, TN EDL and drugs used in RMMCH are tabulated in (Table 4).

\section{Impact of Pharmaceutical Care}

The impact of pharmaceutical care among test and control group was measured using various assessments such as (lung function tests, handling of inhalers, Quality of life and medication adherence). FEV (Forced Expiratory Volume) and FVC (Forced Vital Capacity) tests are used to assess the lung function in test and control groups before and after intervention (as shown in Table 5) and their statistical significance differences were measured. Improvement in handling of inhalers in between test and control were tabulated in (Table 6). By using the paediatric asthma care givers quality of life questionnaire mean values are noted in both test and control group before and after the intervention. These mean values are noted in (Table 7). Medication adherence results are noted for follow up periods in test and control groups.

The following tabular column represents the differences in mean values of forced vital capacity and forced expiratory volume ${ }_{1}$ in test and control groups before and after the intervention.

\section{DISCUSSION}

\section{PATIENT DEMOGRAPHIC CHARECTERISTICS}

A total number of 67 patients were enrolled during the study period. Of these, 61 patients completed study. In comparison with earlier studies, ${ }^{11,12,14}$ asthmatic attacks were found to be more common in male than female patients in the present study. Almost $40 \%$ of patients were in the age group of $9-12$ years. Rest, around $60 \%$ were in the $0-8$ year's age group. Our findings correlates with the study conducted, ${ }^{11}$ puerility asthma is the

\begin{tabular}{ccc} 
Table 2: Categories of Drugs Used & \\
\hline Catrgory & Name of drugs & No. of prescription \\
\hline CORTICOSTEROIDS & $\begin{array}{c}\text { Hydrocortisone, Prednisolone, } \\
\text { Beclomethasone }\end{array}$ & 25 \\
$\beta$-AGONIST & Salbutamol, Ipratropium bromide & 51 \\
METHYLXANTHINE & Theophylline & 23 \\
ANTIHISTAMINES & Epinephrine & 13 \\
ANTIBIOTICS & Crystalline penicillin, Amikacin, Amoxicillin. & 22 \\
ANTITUSSIVES & Mucolytics, Cough suppressants & 24 \\
\hline
\end{tabular}

Table 3: List of Anti-Asthmatic Drugs in RMMCH, WHO EDL, National EDL \& TN EDL

\begin{tabular}{|c|c|c|c|c|c|c|c|c|c|}
\hline \multicolumn{4}{|c|}{ Total no. of anti-asthmatic drugs } & \multicolumn{3}{|c|}{ No. of drug belonging to } & \multicolumn{3}{|c|}{$\%$ of drug belonging to } \\
\hline $\begin{array}{l}\text { IN WHO } \\
\text { EDL }\end{array}$ & $\begin{array}{c}\text { IN NATIONAL } \\
\text { EDL }\end{array}$ & IN TN EDL & IN RMMCH & WHO & N EDL & TN EDL & WHO EDL & N EDL & TN EDL \\
\hline 5 & 4 & 5 & 5 & 3 & 4 & 2 & $60 \%$ & $100 \%$ & $40 \%$ \\
\hline
\end{tabular}


Table 4: List of Anti-Asthmatic Drugs in Rmmch, Who Edl, National Edl \& Tn Edl DRUGS LIST IN NATIONAL

BECLOMETASONE Inhalation
(aerosol):100 mcg per dose.

BUDESONIDE Inhalation (aerosol):100 mcg; $200 \mathrm{mcg}$ per dose.

EPINEPHRINE Inj. 1mg in 1-ml ampoule

IPROTROPIUM BROMIDE Inhalation (aerosol): 20 mcg

SALBUTAMOL Neb: 5 mg; Inj: 50 mg. Inhalation (aerosol):100 mg

\section{DRUGS LIST IN TN-EDL}

DRUGS LIST IN RMMCH EDL

\section{IPRATROPIUM BROMIDE Inhalation $20 \mathrm{mcg} / \mathrm{metered}$ dose}

SALBUTAMOL Tab $2 \mathrm{mg}, 4 \mathrm{mg}$ Syrup $2 \mathrm{mg} / 5 \mathrm{ml}$ Inhalation 100 $\mathrm{mcg} / \mathrm{dose}$

BECLOMETHASONE DIPROPIONATE Inhalation: $50 \mathrm{mcg}, 250 \mathrm{mcg} / \mathrm{dose}$.

HYDROCORTISONE SODIUM SUCCINATE Injection : 100 $\mathrm{mcg}, 200 \mathrm{mcg}, 400 \mathrm{mcg}$
THEOPHYLLINE \&

ETOPHYLLINE Anhydrous theophylline $50.6 \mathrm{mg}$ Etophylline $169.4 \mathrm{mg}$

THEOPHYLLINE IP 23 mg

\section{ETOPHYLLINE IP 77 mg}

SALBUTAMOL Nebulizer- 5 $\mathrm{mg} / \mathrm{ml}$
SALBUTAMOL

THEOPHYLLINE

IPRATROPIUM BROMIDE

BUDESONIDE
SALBUTAMOL SULPHATE Tab I.P $4 \mathrm{mg}$

\begin{tabular}{|c|c|c|c|}
\hline & & FVC & $\mathrm{FEV}_{1}$ \\
\hline \multirow{2}{*}{ TEST } & BEFORE & $3.08 \pm 0.27$ & $2.41 \pm 0.76$ \\
\hline & AFTER & $3.39 \pm 0.32$ & $2.97 \pm 0.82$ \\
\hline \multirow{2}{*}{ CONTROL } & BEFORE & $2.66 \pm 0.19$ & $2.39 \pm 0.76$ \\
\hline & AFTER & $2.85 \pm 0.29$ & $2.42 \pm 0.77$ \\
\hline
\end{tabular}

FVC *The difference in the mean values of the two groups (test and control) is greater than would be expected byChance; there is a statistically significant difference between the input groups $(P=<0.001) . t=2.803$. * For control group $t=0.803$ $(P=0.425)$.

FEV1 $*$ The difference in the mean values of the two groups (test and control) is greater than would be expected byChance; there is a statistically significant difference between the input groups $(P=<0.008) . t=2.743$. * For control group $t=0.154$ $(P=0.878)$.

\begin{tabular}{cccc}
\multicolumn{4}{c}{ Table 6: Assessment for Handling of Inhalers } \\
\hline Trained & Correct Users & Incorrect Users & P value \\
\hline Test & $15(48.3 \%)$ & $16(51.6 \%)$ & 0.121 \\
Control & $3(10 \%)$ & $27(90 \%)$ & \\
\hline
\end{tabular}

Significance was found out by comparing the calculating t value with tabulated t value at $95 \%$ confidence interval $(p=0.016)$.

Table 7: Assessment of Quality Of Life

\begin{tabular}{lccc} 
& Pre intervention & Post intervention & Significance \\
\hline Test & $45.21 \pm 5.83$ & $58.21 \pm 7.86$ & YES \\
Control & $44.73 \pm 5.84$ & $48.59 \pm 6.36$ & YES \\
\hline * The difference in the mean values of the two groups (test and control) is greater than would be expected by Chance; there \\
is a statistically significant difference between the input groups $(P=<0.001) . t=7.396 *$ For non-interventional group $t=1.844$ \\
$(P=0.070)$.
\end{tabular}

Table 8: Medication Adherence

\begin{tabular}{cccccccc} 
& \multicolumn{3}{c}{ FOLLW UP 1 } & \multicolumn{3}{c}{ FOLLOW UP 2 } \\
\cline { 2 - 7 } & L & M & H & L & M & H \\
\hline TEST & 2 & 17 & 12 & 0 & 12 & 19 \\
CONTROL & 7 & 22 & 2 & 9 & 21 & 1 \\
\hline
\end{tabular}

$\mathrm{L}=$ low, $\mathrm{M}=$ medium, $\mathrm{H}=$ high. 


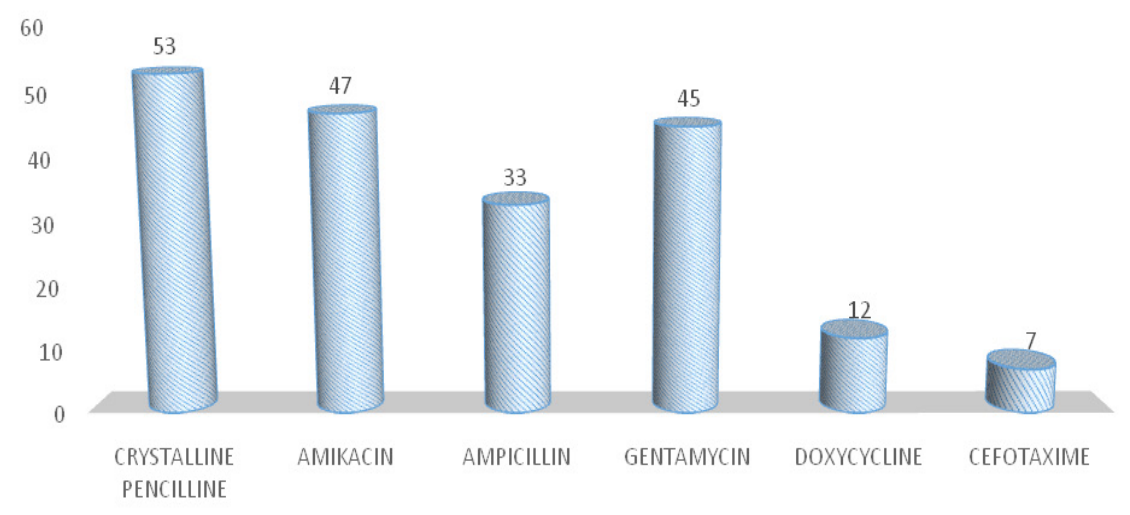

Figure 2: Antibiotics Prescribed

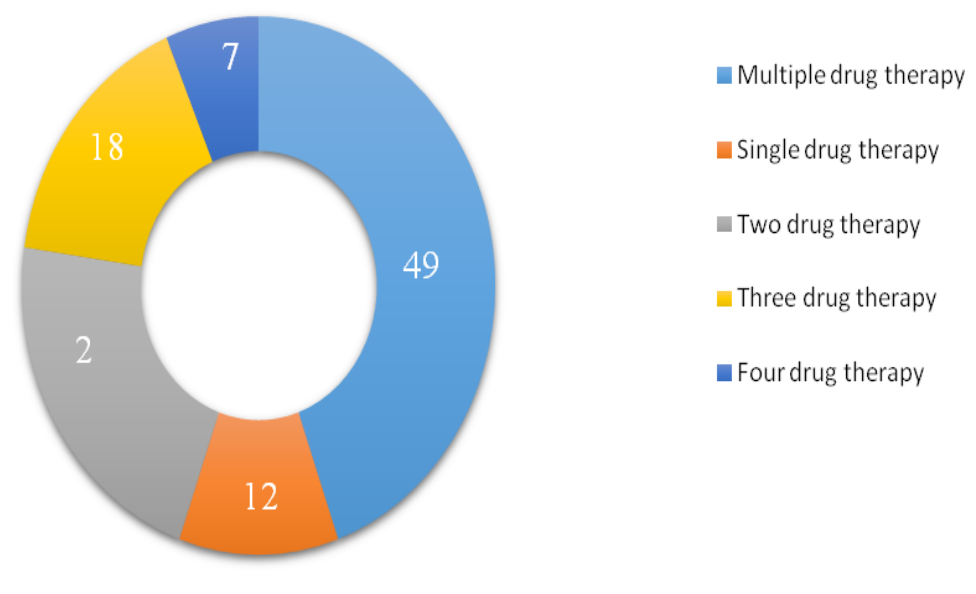

Figure 3: Drug Therapy Regimen

most predominant chronic condition and further study findings shows consistent higher prevalence rates, with $\sim 10 \%$ in children. More than the half i.e., $57.3 \%$ of patients have moderate asthma, following with mild and severe. This study shows the main cause of asthma is climate which accounts for $55 \%$, dust for $27.8 \%$, and other causes accounts for $22.2 \%$ (pollens and drugs).

\section{PRESCRIBING PATTERN}

The choice of drug depends on the proper classification of the severity of attack that occurs. In this study, average number of anti-asthmatic drugs prescribed per patient was 3.5.

Multi drug therapy was the most common type of therapy identified in this study, which is consistent with the findings of other studies. ${ }^{10}$ It accounts for $80.32 \%$ of all the prescription. Among the $40.98 \%$ of prescriptions that had polytherapy, $19.6 \%$ of prescription consisted of mono therapy depicted in Figure 3.

Salbutamol ( $\beta$-agonists) $(83.60 \%$ ) was the most commonly used bronchodilator followed by theophylline (methyl xanthine's) (37.70\%). Corticosteroids (hydrocortisone, dexamethasone, and prednisolone) are prescribed in 25 (40.98\%) prescriptions. ${ }^{10,13,17}$ Anti-tussives, antibiotics and anti-histamines are prescribed in 24 (39.34\%), 22 (36.06\%), $13(21.31 \%)$ prescriptions respectively as depicted in Figure 2.

On comparison of drugs used in RMMCH with essential drug lists of WHO, NATIONAL EDL AND TN EDL we found that $60 \%$ of anti-asthmatics belong to WHO EDL, $100 \%$ to NATIONAL EDL \& $40 \%$ to TNEDL. This implies that treatment strategies of RMMCH are based on WHO recommendations. 


\section{IMPACT OF PHARMACEUTICAL CARE}

Controlling Bronchial asthma with minimal adverse effects and maintaining the patient's ability to perform daily activities are the critical measures of treatment outcome. In this study, the outcome of the pharmaceutical care was measured in terms quality of life, assessing inhalation techniques, medication adherence. Serious problems like medication in adherence leads to increased burden on health care system. Thus, pharmaceutical care explicitly shows the pharmacist crucial role in the improvement of patient's health related quality of life, rather than simply providing a product or service. Pharmaceutical care activities are particularly important when caring for patients with chronic disease, where it is estimated that over $50 \%$ of patients do not take their medication properly. In the present study, we examined the impact of a pharmaceutical care program implemented to improve outcomes and optimize quality of life in patients with bronchial asthma. In the asthmatics, the intervention group had a better general health, higher activity, and less impact on their daily life, as detected by asthma care givers questionnaire, compared with the control group. Our study indicated that patients are benefited with continual patient's education ${ }^{15}$ assessed the effect of patient education on HRQoL (Health Related Quality of Life) in a randomized controlled study on asthma and COPD (Chronic Obstructive Pulmonary Disease) and they observed, after one year follow up, a clear improvement in the intervention group relative to the control group among asthmatics. ${ }^{16}$ The intervention group, in the asthmatic patients of our study, had overall positive clinical outcomes. They had improved $\mathrm{FEV}_{1} \& \mathrm{FVC}$, less symptoms, exacerbation, improved medication adherence and better handling of inhalers, compared with the control group. Statistically significant differences between the control and the intervention groups were noted regarding FVC \& FEV Statistically significant changes were also observed in the QoL of patients with asthma compared with non interventional group. This difference can be attributed to better understanding of disease and risk factors, thereby avoiding the trigger factors which lead to lower number of attacks and hospital visits.

Improvement in usage of inhaler is observed in interventional group compared to non interventional group when assessed based on the stages involved in inhalation technique.

\section{MEDICATION ADHERENCE}

Remarkable improvement in adherence is observed in interventional group after follow-up two (shown in Table 8). This improvement can be attributed for better understanding of drugs by patient due to patient education. These results suggest that more involvement of pharmacist in patient care yields better therapeutic outcomes.

\section{CONCLUSION}

Our study showed that male is more affected with asthma than female. Patients of age group $8-12$ more affected than any other age groups. B-agonists and corticosteroids are the most commonly prescribed drugs for asthma followed by methylxanthines and anti-tussives. Most of the treatment strategies are adopted from WHO guidelines and WHO EDL. Patient education increased the knowledge about Asthma and importance of self-care, and lifestyle modifications that can lead to better control of the disease among the patients. By the end of our study there was a significant increase in the medication adherence score. It is evident that Patient education produced a significant improvement in quality of life, medication knowledge and the effect in adherence behaviour. By the end of our study there was a significant increase in the mean score of QoLin the test group. At base line all patients had poor knowledge and attitude towards their disease and thus poor QoL. At the end of the study patients of interventional group received extensive education regarding their disease and its management showed greater improvement in treatment outcomes than in patients in control group.Medications and hospitalization charges account for the most part of direct cost can be overcome due to patient's education.Medication adherence results suggest that more involvement of pharmacist in patient care yields better therapeutic outcomes. Pharmacist holds an important role in educating the patient about disease there by avoiding the trigger factors and reducing the hospitalizations. In conclusion, patient counselling aided and had a positive impact on patient's understanding of their illness and the role of medications in its treatment, improved medication adherence, and improved Quality of life for the patients. Moreover, a good professional rapport has been built between the Pharmacist and the Patient.

\section{CONFLICT OF INTEREST}

The author has no conflict of interest

\section{ACKNOWLEDGEMENTS}

We express our profound \& sincere gratitude to Dr.S.Parimalakrishnan, Assistant Professor, Dr. P.K. Manna, Professor, Department Of Pharmacy, and Dr. C.S. Balachandran, MD D.C.H, Professor, Department 
Of Pediatrics, RMMCH Annamalai University, Annamalai Nagar, for their valuable guidance and support, constant inspiration, kind co-operation and great intend to us to fulfill our work in a successful manner.

\section{Highlights of Paper}

- Made a clear attempt to show the general prescribing pattern of physicians in bronchial asthmatic paediatric patients.

- Impact of pharmaceutical care was evaluated and shown how significant the impact was.

- Pharmaceutical care is provided and emphasized its importance in pediatric patients.

\section{Author Profile}

- V. Bhavan kumar: Completed 5 years PHARM D. and presently working as intern in super speciality hospital rajah muttiah medical college and hospital Annamalai University, Tamil nadu. I have2 review papers in different journals and this is myfirst research article. I am intrested inthe fields of clinical research, clinical pharmacy, pharmacovigilance, public health sciences. Having an experience indesigning patient's therapeutic plan and providing pharmaceutical care, participating in daily ward rounds, patient counselling, Assessment of drug related problems, measurement of therapeutic outcomes and drug information services in wards like obstetrics and gynaecology, paediatrics, surgery and general medicine..

\section{REFERENCES}

1. Joseph Dipiro T, Robert Talbert L, Gary Yee C, et al. pharmacotherapy A Pathophysiologic Approach. $7^{\text {th }}$ edition. McGraw hill; 463.

2. Johnston SL, Holgate ST, editors. Asthma: critical debates. London: Blackwell science; 2003.

3. Rabe KF, Adachi M, Lai CK. Worldwide severity and control of asthma in children and adults: the global asthma insights and reality surveys. J Allergy Clinlmmunol. 2004; 114(1): 40-7.

4. Herfindal Eric T, Helms RA, Quinn DJ. Text book of Therapeutics. 2nd ed. Lippincot William and Wilkins; 2002. 658-81.

5. World health organization. bronchial asthma, fact sheet $\mathrm{N}^{\circ} 206$. [Internet] Available from: http://www.who.int/mediacentre/factsheets.

6. Donahue JG, Weiss ST, Livingstone JM, et al. Inhaled steroids and the risk of hospitalization for asthma. JAMA. 1997; 277(11): 887-91.

7. Martin Schulz, Frank Verheyen, et al. pharmaceutical care services for asthma patients a controlled intervention study. Journal of clinical pharmacology. The American college of clinical pharmacology 2001; 41(1): 668-76.

8. Book of adherence to long term therapies- evidence for action- $\mathrm{WHO} ; 2003.20$.

9. Morisky DE, Ang A, Krousel-Wood M, Ward HJ. Predictive validity of a medication adherence measure in an outpatient setting. J Clins Hypertens. 2008; 10(5): 348-54.

10. Patel Pinal D, patel RK, patel NJ, et al. Analysis of prescription pattern and drug utilization in asthma therapy. IRJP. 2012; 108(1): 257
11. Stock S, Redaelli M, Luengen M, Wendland G, Civello D. Lauterbach Asthma: prevalence and cost of illness. Eur Respir J. 2005; 25: 47-53

12. Wendy Ungar J, Peter Coyte C, et al. Prospective Study of the PatientLevel Cost of Asthma Care in Children. Pediatric Pulmonology 2001; 32(2): 101-8.

13. Chamanpreet S, Gandhi, et al. Assessment of Quality of Life in Children with Asthma and Epilepsy Pediatrics. an open access journal ISSN: 21610665.

14. Mike Thomas, Tarita Murray-Thomas, Tao Fan. Prescribing patterns of asthma controller therapy for children in UK primary care: a cross-sectional BMC Pulmonary Medicine 2010; 10(1): 29. http://www.biomedcentral. com/1471-2466/10/29

15. Gallefoss F, Bakke PS, Rsgaard P. Quality of life assessment after patient education in a randomized controlled study on asthma and chronic obstructive pulmonary disease. Am. J. Respir. Crit. Care Med. 1999; 159(3): 812.

16. Jones PW, Quirk FH, Baveystock CM, Littlejohns P. A self-complete measure of health status for chronic airflow limitation. Am. Rev. Respir. Dis. 1992; 145(6): 1321-7.

17. Arellano FM, Arana A, Wentworth CE, Vidaurre CF, Chipps BE. Prescription patterns for asthma medications in children and adolescents with health care insurance in the United States. Pediatr Allergy Immunol. 2011; 22(5): 469-76. 